\title{
Mutations in the RET proto-oncogene and the von Hippel-Lindau disease tumour suppressor gene in sporadic and syndromic phaeochromocytomas
}

CRC Human Cancer Genetics Research Group, University of Cambridge,

Addenbrooke's

Hospital, Box 238,

Level 3 Laboratories

Block, Hills Road, Cambridge CB2 2QQ UK

C Eng

L M Mulligan

C S Healey

C Houghton

D P Smith

B A J Ponder

Division of Cancer

Epidemiology and

Control, Dana-Farber

Cancer Institute,

Department of

Medicine, Harvard

Medical School,

Boston, USA

C Eng

Molecular Genetics Group, Department of Pathology, University of Cambridge,

Cambridge, UK

P A Crossey

A Prowse

E R Mahe

Departments of Paediatrics and Pathology, Queen's

University, Kingston,

Canada

L M Mulligan

Department of Endocrinology,

St Bartholomew's

Hospital, London, UK

$S$ L Chew

P L M Dahia

Endocrine Genetics Unit, University of São Paulo School of Medicine, São Paulo, Brazil

P L M Dahia

S P A Toledo

Department of

Metabolic Medicine,

Middlesex Hospital,

London, UK

J L H O'Riordan

Department of

Clinical Genetics,

Addenbrooke's

Hospital, Box 134 ,

Cambridge CB2 2QQ,

E R Maher

Correspondence to: Professor Ponder or Dr Maher.

Received 11 July 1995 Revised version accepted fo publication 31 August 1995

Charis Eng, Paul A Crossey, Lois M Mulligan, Catherine S Healey, Carol Houghton, Amanda Prowse, Shern L Chew, Patricia L M Dahia, Jeffrey L H O'Riordan, Sergio P A Toledo, Darrin P Smith, Eamonn R Maher, Bruce A J Ponder

\section{Abstract}

Phaeochromocytomas may occur sporadically, or as part of the inherited cancer syndromes multiple endocrine neoplasia (MEN) type 2, von Hippel-Lindau disease (VHL), and, rarely, in type 1 neurofibromatosis. In MEN 2, germline missense mutations have been found in one of eight codons within exons $10,11,13,14$, and 16 of the RET proto-oncogene. In VHL, germline mutations within one of the three exons are responsible for the majority of cases. To determine if somatic mutations similar to those seen in the germline in MEN 2 or VHL disease play a role in the pathogenesis of sporadic or familial phaeochromocytomas, we analysed 48 sporadic tumours and tumours from $17 \mathrm{MEN} 2$ and five VHL patients for mutations in RET exons $9,10,11,13,14,15$, and 16 , and the entire coding sequence of VHL. Five of 48 sporadic phaeochromocytomas had RET mutations within exons 10,11 , and 16 . Of these, one was proven to be germline and two were proven to be somatic mutations. Four of 48 had VHL mutations; these included both the bilateral cases in the series (one was proven to be a germline mutation) and two others, of which one was proven somatic.

(f Med Genet 1995;32:934-937)

Phaeochromocytomas usually occur sporadically but are also a feature of three inherited cancer syndromes with an autosomal dominant pattern of inheritance: von Hippel-Lindau disease (VHL), multiple endocrine neoplasia type 2 (MEN 2), and type 1 neurofibromatosis. ${ }^{1-5}$ The major components of VHL include retinal and cerebellar haemangioblastomas, renal cell carcinoma, phaeochromocytoma, and renal, pancreatic, and epididymal cysts. ${ }^{2}$ The frequency of phaeochromocytomas in affected subjects within a particular VHL family can range from 0 to $>90 \%$, with a mean of $14 \% .^{6-8}$ MEN 2 is divided into three subtypes according to the tissues involved. ${ }^{34} \mathrm{MEN} 2 \mathrm{~A}$ is characterised by the presence of MTC, phaeochromocytoma, and hyperparathyroidism, and MEN 2B by MTC, phaeochromocytoma, and developmental abnormalities such as gan- glioneuromatosis and marfanoid habitus. Familial MTC (FMTC) comprises MTC as the only disease phenotype. In MEN 2, approximately $40 \%$ of affected subjects have phaeochromocytoma. ${ }^{9} \quad$ Although phaeochromocytoma is clearly a feature of type 1 neurofibromatosis, its frequency is only about $1 \%{ }^{1}$

The susceptibility genes for VHL and MEN 2 have been identified using positional cloning techniques. Germline deletions and intragenic mutations have been detected along the length of the VHL tumour suppressor gene, which encodes a protein of unknown function, in approximately $70 \%$ of VHL kindreds. ${ }^{1011}$ In the majority of families with the three MEN 2 syndromes, germline missense mutations have been found in one of eight codons of the RET proto-oncogene, which codes for a receptor tyrosine kinase. ${ }^{12-20}$ Mutation in one of codons $609,611,618,620$ (exon 10), 634 (exon 11), 768 (exon 13), or 804 (exon 14) is responsible for the majority of MEN 2A and FMTC families, while a missense mutation in methionine codon 918 (exon 16) is responsible for $>93 \%$ of MEN 2B cases. $^{20}$

To determine if somatic RET and VHL mutations play a role in tumour progression in sporadic or familial phaeochromocytomas, mutation analyses of the VHL gene and those exons of the RET proto-oncogene which have been shown previously to be involved in MEN 2 or MTC were performed in phaeochromocytomas from sporadic cases and from MEN 2 and VHL patients.

\section{Materials and methods}

PHAEOCHROMOCYTOMAS

A total of 70 phaeochromocytomas, 48 sporadic, 17 from MEN 2 cases, and five from VHL cases, were analysed. All phaeochromocytomas were obtained as frozen tumours. Results of a more limited analysis of RET in 15 of the 48 sporadic tumours and five of the 17 MEN 2 tumours have previously been reported in two independent studies. The first included 12 sporadic phaeochromocytomas and five MEN 2 tumours analysed for somatic mutations in exons 10,11 , and 16 only. ${ }^{16}$ The second included a total of three sporadic tumours analysed for exons 10 and 11 only. ${ }^{21}$ 
Table 1 RET mutations in apparently sporadic phaeochromocytomas

\begin{tabular}{|c|c|c|c|c|}
\hline & $\begin{array}{l}\text { This study } \\
(n=48)\end{array}$ & $\begin{array}{l}\text { Kominoth et } a l^{24} \\
(n=7)\end{array}$ & $\begin{array}{l}\text { Lindor et } a l^{25} \\
(n=29)\end{array}$ & $\begin{array}{l}\text { Beldjord et } a l^{2} \\
(n=28)\end{array}$ \\
\hline Exon 9 & 0 & Not analysed & Not analysed & $\begin{array}{l}1 \\
\text { del AG }\end{array}$ \\
\hline Exon 10 & $\stackrel{2}{\mathrm{C}} 620 \mathrm{Y}^{*}$ & 0 & 1 & \\
\hline Exon 11 & C634G† & 0 & $\begin{array}{l}1 \\
\text { del } 632-633\end{array}$ & $\begin{array}{l}2 \\
\text { D631Y* } \\
\text { C634W* }\end{array}$ \\
\hline $\begin{array}{l}\text { Exon } 13 \\
\text { Exon } 15 \\
\text { Exon } 16\end{array}$ & $\begin{array}{l}0 \\
0 \\
2 \\
\text { M918T }\end{array}$ & $\begin{array}{l}\text { Not analysed } \\
\text { Not analysed } \\
0\end{array}$ & $\begin{array}{l}\text { Not analysed } \\
\text { Not analysed } \\
2 \\
\text { M918T } \\
\text { D925H* }\end{array}$ & $\begin{array}{l}\text { Not analysed } \\
\text { Not analysed } \\
3 \\
\text { M918T }\end{array}$ \\
\hline Total mutations & $5(10.4 \%)$ & $0(0 \%)$ & $3(10 \cdot 3 \%)$ & $6(21 \cdot 4 \%)$ \\
\hline
\end{tabular}

* No corresponding germline DNA available.

t Proven germline mutation.
The other cases are proven somatic mutations.

Table 2 VHL mutations in apparently sporadic phaeochromocytoma

\begin{tabular}{|c|c|c|c|c|c|}
\hline Patient ID & Clinical & $\begin{array}{l}\text { Nucleotide } \\
\text { change }\end{array}$ & $\begin{array}{l}\text { Amino acid } \\
\text { change }\end{array}$ & Exon & Origin \\
\hline AG & $\begin{array}{l}\text { Sporadic, } \\
\text { bilateral }\end{array}$ & $553 \mathrm{G} \rightarrow \mathrm{A}$ & $\begin{array}{l}185 \\
\text { Gly } \rightarrow \text { Ser }\end{array}$ & 1 & $\begin{array}{l}\text { Probably } \\
\text { germline }\end{array}$ \\
\hline 333 & $\begin{array}{l}\text { Sporadic, } \\
\text { bilteral }\end{array}$ & $569 \mathrm{~T} \rightarrow \mathrm{C}$ & $\begin{array}{l}190 \\
\text { Phe } \rightarrow \text { Ser }\end{array}$ & 2 & Germline \\
\hline 335 & $\begin{array}{l}\text { Sporadic, } \\
\text { unilateral }\end{array}$ & $642 \mathrm{C} \rightarrow \mathrm{G}$ & $\begin{array}{l}214 \\
\text { Asp } \rightarrow \text { Glu }\end{array}$ & 2 & $?$ \\
\hline 343 & $\begin{array}{l}\text { Sporadic, } \\
\text { unilateral }\end{array}$ & $704 \mathrm{~A} \rightarrow \mathrm{G}$ & $\begin{array}{l}235 \\
\text { Gln } \rightarrow \text { Arg }\end{array}$ & 3 & Somatic \\
\hline
\end{tabular}

A phaeochromocytoma was considered sporadic if there was no history of a first or second degree relative with MTC or phaeochromocytoma and there were no other stigmata of MEN 2, VHL, or neurofibromatosis recorded by the clinician providing the material. Among this set of 48 apparently sporadic tumours were 46 unilateral, unifocal tumours (of which one was malignant) and two bilateral tumours. The MEN 2 cases belong to families in which the diagnosis had been made based on pathology of thyroid and adrenal tumours. VHL disease was diagnosed according to standard criteria. ${ }^{2}$ In these MEN 2 and VHL cases, germline mutations in the RET proto-oncogene and the VHL gene have been identified. ${ }^{101420}$

ISOLATION OF DNA

Genomic DNA and cDNA were prepared from frozen tissues as described previously ${ }^{1622}$ and from peripheral blood leucocytes using an automated DNA extractor (Applied Biosystems).

PCR AMPLIFICATION AND MUTATION ANALYSIS Genomic amplicons encompassing exons 7 to 19 of the RET proto-oncogene were created by the polymerase chain reaction (PCR). Primers used in these analyses were as follows: CRT $10 \mathrm{G}$ and CRT 10H (exon 7), CRT 10D and 18C (exon 8), CRT 18D and 18E (exon 9), CRT 19S and 2C (exons 10 and 11), CRT 19S and CRT 19E (5'GGA CCT CAG ATG TGC TGT T 3') (exon 10), CRT 19B and CRT 2C (exon 11), CRT 1B and 4C (exon 12), CRT $4 \mathrm{E}$ and $4 \mathrm{~F}$ (exon 13), CRT $4 \mathrm{~N}$ and $4 \mathrm{~K}$ (exon 14), CRT 17B and 17G (exon 15), CRT $5 \mathrm{G}$ and CRT $5 \mathrm{H}$ or $\mathrm{R}$ RET 16 and $\mathrm{r}$ RET 16 (exon 16), CRT 5J and 6E (exon 17), CRT $6 \mathrm{~B}$ and $6 \mathrm{E}$ (exon 18), and CRT $6 \mathrm{~J}$ and $14 \mathrm{~K}$ (exon 19). ${ }^{1214-161823}$ Fifty to $100 \mathrm{ng}$ of genomic DNA were amplified using the conditions previously described, ${ }^{1416}{ }^{23}$ except for an annealing temperature of $58^{\circ} \mathrm{C}$ for $f$ RET 16 and $\mathrm{r}$ RET $16 .{ }^{15}$ Amplicons created from cDNA templates were as previously described. ${ }^{1216}$ If PCR was carried out using the "Red Hot" Thermus icelandicus DNA polymerase according to the manufacturer's recommendations (Advanced Biotechnologies, Surrey, UK), commercially supplied buffer with $1.5 \mathrm{mmol} / 1 \mathrm{MgCl}_{2}$ was used and, in general, annealing temperatures were raised by $3-5^{\circ} \mathrm{C}$.

PCR products were purified by electrophoresis through low melting point agarose and eluted using the Wizard PCR Prep kit (Promega, Southampton, UK) before sequencing. Purified amplification products were sequenced using the appropriate primer with the $\Delta T a q$ Version 2.0 cycle sequencing kit (USB, Cleveland, Ohio, USA) or the Cyclist sequencing kit (Stratagene, Cambridge, UK) according to the manufacturers' recommendations, and resolved on $6 \%$ denaturing polyacrylamide gels.

All tumour samples were analysed by direct sequence analysis or by appropriate restriction enzyme digestions for known mutations in RET exons 9, 10,11, 13, 14, 15, and $16 . .^{14161819}$ Thus, the 12 sporadic and five MEN 2 phaeochromocytomas previously analysed at exons 10,11 , and $16^{16}$ were further analysed for mutations in exons $9,13,14$, and 15 in this study; the three sporadic tumours previously analysed for exons 10 and $11^{21}$ were also further analysed for mutations in exons $9,13,15$, and 16. In addition, DNA from 12 sporadic tumours was analysed by sequencing exons 7-19, which code the entire cystein rich and tyrosine kinase domains of RET.

Mutations analysis for the VHL gene was performed using six primer pairs. Each PCR fragment was analysed by single strand conformational polymorphism (SSCP) and heteroduplex analysis as previously described. ${ }^{10}$ Samples showing aberrant band patterns were sequenced directly using nested primers.

\section{Results}

\section{SPORADIC PHAEOCHROMOCYTOMAS}

Of 48 sporadic phaeochromocytomas, five had mutations in the RET proto-oncogene and four others in the VHL gene (tables 1 and 2). The only malignant tumour in this series did not have mutations. Among the tumours with RET mutations, two had somatic codon 918 mutations altering ATG to ACG (M918T), which were not present in germline (peripheral blood) DNA. One of these two M918T mutations has been reported previously. ${ }^{16}$ One tumour had a codon 634 TGC to GGC mutation (C634G); when germline DNA was examined, the mutation was also detected in the germline. This patient had no other stigmata of MEN 2, and did not have a family history of MEN 2, MTC, or phaeochromocytoma elicited by the clinician at the time of operation. Once this unexpected germline mutation was detected in the proband, her first degree relatives were examined 
for the presence of the germline mutation. Her father and two of three of her sibs carried this mutation. Subsequent history showed that the grandfather "died of a goitre" and examination of the proband's father showed a thyroid mass and bilateral phaeochromocytomas. Two other tumours had codon 620 TGC to TAC mutations (C620Y). ${ }^{16}$ Unfortunately, germline DNA was not available from these two cases with mutation at codon 620 . Of the four tumours which carried VHL mutations, two had exon 2 missense mutations (F190S, D214E), one had an exon 1 missense mutation (G185S), and one had an exon 3 missense mutation (Q235R) (table 2). The Q235R mutation occurred in a patient with unilateral disease and was proven to be somatic. The F190S mutation occurred in a patient with bilateral phaeochromocytoma diagnosed at the age of 11 years and this mutation was detected in both tumours and the germline. The patient, whose tumour contained the G185S mutation, also had bilateral tumours and the same mutation was detected in both tumours, suggesting that this mutation was also germline in origin. The D214E mutation occurred in a patient with unilateral disease but no germline DNA was available. Of these four patients with VHL mutations, none had other clinical signs of VHL disease nor family histories of VHL or phaeochromocytomas.

A more extensive search for mutations, encompassing RET exons 7-19, coding for the cysteine rich domain and the tyrosine kinase domain, was carried out in 12 sporadic phaeochromocytomas. No further mutations were detected. In addition, two sporadic phaeochromocytomas, previously postulated not to express the region of RET exons 10 or 11 because of failure to amplify by RT-PCR with primers encompassing those exons, ${ }^{21}$ have subsequently been shown to amplify the region of RET exons 10 and 11 by RT-PCR using different sets of primer pairs. No mutations were detected.

PHAEOCHROMOCYTOMAS FROM MEN 2 CASES Neither somatic RET mutations in exons 9, $10,11,13,14,15$, or 16 nor VHL mutations were detected in tumours from MEN 2A and MEN 2B patients. Germline RET mutations have been previously reported in each of these patients. ${ }^{121416}$

PHAEOCHROMOCYTOMAS FROM VHL CASES Apart from the germline VHL mutations detected in tumour tissue, no somatic RET and VHL mutations were detected. The germline mutations were detected in the heterozygous state in each of the tumours. Loss of heterozygosity $(\mathrm{LOH})$ studies using $3 \mathrm{p}$ markers flanking the VHL gene were performed on three of these tumours (and compared to the allele pattern obtained in germline DNA). In two, all markers were uninformative (that is, either homozygous or hemizygous) and the third showed retention of heterozygous markers (data not shown).

\section{Discussion}

We found RET mutations in approximately $10 \%$ of sporadic phaeochromocytomas. This is consistent with other reports (summarised in table 1). ${ }^{2526}$ All MEN 2 germline mutations ${ }^{20}$ and MTC somatic mutations described to date lie within the region of the gene covered in this analysis. ${ }^{151618-2027-29}$ However, the results of this study and others ${ }^{2526}$ suggest that a wider spectrum of RET mutations can occur in sporadic phaeochromocytomas than in sporadic MTC, including some mutations, such as the exon 9 splice site mutation ${ }^{26}$ and the two codon deletion in exon $11,{ }^{25}$ not so far found in the MEN 2 syndromes. This raises the possibility that other mutations may be present elsewhere in RET in these tumours. We sequenced exons 7-19 and found no mutations in a sample of 12 tumours, but it is possible that such mutations could rarely be present in the $5^{\prime}$ region of the gene or the introns. Alternatively, other genes may be involved.

Phaeochromocytomas are a component of VHL. ${ }^{2}$ Five of nine sporadic phaeochromocytomas and five of nine MEN 2 phaeochromocytomas were previously shown to have LOH at $3 p$ markers, ${ }^{30}$ suggesting the putative involvement of the VHL gene, which lies on chromosome arm $3 \mathrm{p}$, in tumour progression. Unexpectedly, we found VHL mutations in only $8 \%$ of apparently sporadic tumours: one was proven somatic, two were probably germline, and one was undetermined (summarised in table 2). Two of the four VHL gene missense mutations are new. ${ }^{1031-34}$ No somatic VHL mutations were identified in nine sporadic phaeochromocytomas studied by Gnarra et al. ${ }^{32}$ Together with our series, only one proven somatic VHL mutation has been detected in 57 sporadic phaeochromocytomas. The rarity of somatic VHL mutations in sporadic phaeochromocytomas contrasts with their frequent presence in sporadic clear cell renal cell carcinoma, a tumour which is a component of VHL. ${ }^{31-33}$ The discrepancy between the paucity of VHL mutations in sporadic phaeochromocytomas and the frequent finding of LOH on $3 p$ raises the possibility that the $3 p$ LOH may reflect mutation in a gene which lies in the $3 p$ region but is distinct from VHL, analogous to the findings in sporadic Wilms' tumours. ${ }^{35}$

We detected no somatic VHL mutations in the second allele in five phaeochromocytomas from VHL cases. The VHL gene is believed to be a tumour suppressor gene. ${ }^{36}$ Consistent with this, germline mutations in the VHL gene are predicted to be inactivating. ${ }^{410}$ Possibly, the second allele in the VHL phaeochromocytomas has been inactivated by loss of all or part of that allele (for example, the two VHL tumours that were uninformative for $3 p$ markers may be hemizygous), or by methylation or an inactivating mutation within the VHL promoter in the remaining allele, which we would not have detected.

The rarity of somatic RET and VHL mutations in sporadic phaeochromocytomas contrasts with the finding that 23 to $40 \%$ of sporadic MTC, in series of 10 or more tumours, 
have a somatic RET codon 918 (MEN 2B type) mutation. ${ }^{15162829}$ There are probably several different pathways which can lead to the genesis of phaeochromocytomas, and any of several genes in these pathways could be the target for somatic mutation and not just RET or VHL. For example, in a series of 20 sporadic MEN 2 and VHL phaeochromocytomas combined, seven were found to have reduced expression of the NF1 gene. ${ }^{37}$ Another possible reason for the low frequency of somatic VHL mutation in sporadic phaeochromocytomas comes from the analogy with the RET 634 mutation, which is the most common germline mutation in MEN $2 \mathrm{~A}^{20}$ yet very infrequent as a somatic mutation in sporadic MTC. ${ }^{29}$ Thus, as has been suggested for RET 634 mutations, ${ }^{29}$ VHL mutations may only promote tumorigenesis if present at a critical period of adrenal chromaffin cell development or cell cycling.

From a clinical standpoint, it may be prudent to consider screening patients with apparently sporadic phaeochromocytomas for inherited mutations in the RET and VHL gene. This is especially true in a case with an apparently sporadic bilateral tumour, where the possibility of heritable disease is high. In unilateral cases, the yield of such mutation analyses is likely to be low, based on the objective evidence (this study; see tables 1 and 2). However, it can be argued that even a few percent chance of detection of an occult or de novo case of MEN $2 \mathrm{~A}$ would be worthwhile in view of the important implications and possible benefits for that person and his family.

The first two authors contributed equally to this work. We would like to thank M Ponder, C Garner, T Stonehouse, P Harrington, $C$ Pye, and J Dearden for assistance. We are grateful to the clinicians who provided clinical material, and G M Besser to the clinicians who provided clinical material, and GM Besser
for his support. This study was funded by the CRC DanaFarber Cancer Institute Fellowship (CE), core and programme Farber Cancer Institute Fellowship (CE), core and programme
grants from the Cancer Research Campaign (BAJP, ERM), grants from the Cancer Research Campaign (BAJP, ERM),
Action Research (ERM), the National Kidney Research Fund Action Research (ERM), the National Kidney Research Fund
(ERM), Kingston General Hospital Foundation (LMM), an (ERM), Kingston General Hospital Foundation (LMM), an
MRC-Canada Operating grant (LMM), the MRC (G84/2983) MRC-Canada Operating grant (LMM), the MRC (G84/2983)
(SLC), and a FAPESP Research Fellowship (PLMD). BAJP is

1 Riccardi VM. Von Recklinghausen neurofibromatosis. $N$ Engl f Med 1981;305:1617-27.

2 Maher ER, Yates JRW, Harries R, Benjamin C, Harris R, Ferguson-Smith $\mathbf{M}$. Clinical features and natural history of von Hippel-Lindau disease. Qf Med 1990;77:1151-63.

3 Schimke R. Multiple endocrine neoplasia: how many syndromes? Am $\mathcal{f}$ Med Genet 1990;37:375-83.

4 Eng C, Ponder BAJ. The role of gene mutations in the genesis of familial cancers. FASEB $\mathcal{F} 1993 ; 7: 910-9$.

5 Neumann HPH, Berger DP, Sigmund G, et al. Pheochromocytomas, multiple endocrine neoplasia type 2, and von Hippel-Lindau disease. $N$ Engl $f$ Med 1994;329: 1531-8.

6 Atuk NO, McDonald T, Wood T, et al. Familial pheochromocytoma, hypercalcemia and von Hippel-Lindau disease: a ten year study of a larger family. Medicine disease: a ten year study of
(Baltimore) 1979;58:209-18.

7 Neumann HPH. Basic criteria for clinical diagnosis and genetic counselling in von Hippel-Lindau syndrome. Vasa 1987;16:220-6

8 Lamiell JM, Salazar FG, Hsia YE. Von Hippel-Lindau disease affecting 43 members of a single kindred. Medicine (Baltimore) 1989;68:1-29.

9 Vasen HFA, Kruseman ACN, Berkel H, et al. Multiple endocrine neoplasia syndrome type 2: the value of screening and central registration: a study of 15 kindreds in The Netherlands. $A m \Im$ Med 1987;83:847-52.

10 Crossey PA, Richards FM, Foster K, et al. Identification of intragenic mutations in the von Hippel-Lindau disease tumour suppressor gene and correlation with disease phenotype. Hum Mol Genet 1994;3:1303-8.

11 Latif $\mathrm{F}$, Tory $\mathrm{K}, \mathrm{Gnarra} \mathrm{J}$, et al. Identification of the von Hippel-Lindau disease tumor suppressor gene. Science 1993;260:1317-20.

12 Mulligan LM, Kwok JBJ, Healey CS, et al. Germ-line mutations of the RET proto-oncogene in multiple endocrine neoplasia type 2A. Nature 1993;363:458-60.

13 Donis-Keller H, Dou S, Chi D, et al. Mutations in the RET proto-oncogene are associated with MEN 2A and FMTC. Hum Mol Genet 1993;2:851-6.

14 Mulligan LM, Eng C, Healey CS, et al. Specific mutations of the RET proto-oncogene are related to disease phenotype in MEN 2A and FMTC. Nature Genet 1994;6:70-4.

15 Hofstra RMW, Landsvater RM, Ceccherini I, et al. A mutation in the RET proto-oncogene associated with multiple endocrine neoplasia type 2B and sporadic medullary thyroid carcinoma. Nature 1994;367:375-6.

16 Eng C, Smith DP, Mulligan LM, et al. Point mutation within the tyrosine kinase domain of the RET protooncogene in multiple endocrine neoplasia type $2 \mathrm{~B}$ and oncogene in multiple endocrine neoplasia type $2 \mathrm{~B}$ and

17 Carlson KM, Dou S, Chi D, et al. Single missense mutation in the tyrosine kinase catalytic domain of the RET protooncogene is associated with multiple endocrine neoplasia type 2B. Proc Natl Acad Sci USA 1994;91:1579-83.

18 Eng C, Smith DP, Mulligan LM, et al. A novel point mutation in the tyrosine kinase domain of the RET protomutation in the tyrosine kinase domain of the RET proto-
oncogene in sporadic medullary thyroid carcinoma and in oncogene in sporadic medullary thyroid carcinom

19 Bolino A, Schuffenecker I, Luo Y, et al. RET mutations in exons 13 and 14 of FMTC patients. Oncogene 1995;10: 2415-9.

20 Mulligan LM, Marsh DJ, Robinson BG, et al. Genotypephenotype correlation in MEN 2: report of the International RET Mutation Consortium. F Intern Med (in press).

21 Chew SL, Lavender P, Jain A, et al. Absence of mutations in the $M E N 2 A$ region of the $R E T$ proto-oncogene in nonMEN 2A phaeochromoctyomas. Clin Endocrinol 1995;42: 17-21.

22 Mathew CGP, Smith BA, Thorp K, et al. Deletion of genes on chromosome 1 in endocrine neoplasia. Nature 1987; 328:524-6.

23 Mulligan LM, Eng C, Attié T, et al. Diverse phenotypes associated with exon 10 mutations of the RET protoassociated with exon 10 mutations of the

24 Kominoth P, Kunz E, Hiort O, et al. Detection of $R E T$ proto-oncogene point mutations in paraffin-embedded pheochromocytoma specimens by nonradioactive singlestrand conformation polymorphism and direct sequencing. Am $\mathcal{F}$ Pathol 1994;145:922-9.

25 Lindor NM, Honchel R, Khosla S, Thibodeau SN. Mutations in the RET protooncogene in sporadic pheochromocytomas. F Clin Endocrinol Metab 1995;80:627-9.

26 Beldjord C, Desclaux-Arramond F, Raffin-Sanson M, et al. The RET proto-oncogene in sporadic pheochromocytomas. Am f Hum Genet Suppl 1994;55:A51 (abstract 270).

27 Dou S, Chi D, Carlson KM, Moley JA, Wells SA Jr, DonisKeller $H$. RET proto-oncogene mutations associated with sporadic cases of medullary thyroid carcinoma. Fifth International Workshop on Multiple Endocrine Neoplasia 1994: 73 (abstract 617).

28 Zedenius J, Wallin G, Hamberger B, Nordenskjold $M$, Weber G, Larsson C. Somatic and MEN $2 A$ de novo mutations identified in the RET proto-oncogene by screening of sporadic MTC:s. Hum Mol Genet 1994;3:1259-62.

29 Eng C, Mulligan LM, Smith DP, et al. Mutations of the RET proto-oncogene in sporadic medullary thyroid carcinoma. Genes Chrom Cancer 1995;12:209-12.

30 Mulligan LM, Gardner E, Smith BA, Mathew CGP, Ponder BAJ. Genetic events in tumour initiation and progression in multiple endocrine neoplasia type 2. Genes Chrom Cancer 1993;6:166-77.

31 Foster K, Prowse A, van den Berg A, et al. Somatic mutations of the von Hippel-Lindau disease tumour suppressor gene in non-familial clear cell renal carcinoma. Hum Mol Genet 1994;3:2169-73.

32 Gnarra JR, Tory K, Weng Y, et al. Mutations of the VHL tumor-suppressor gene in renal-carcinoma. Nature Genet 1994;7:85-90.

33 Whaley JM, Naglisch J, Gelbert L, et al. Germ-line mutations in the von Hippel-Lindau tumor-suppressor gene are similar to somatic von Hippel-Lindau aberrations in sporadic ilar to somatic von Hippel-Lindau aberrations in sporadic

34 Chen F, Kishida T, Yao M, et al. Germline mutations in the von Hippel-Lindau disease tumor suppressor gene: the von Hippel-Lindau disease tumor suppressor gene:

35 Feinberg A. A developmental context for multiple genetic alterations in Wilms' tumour. $\mathcal{f}$ Cell Sci 1994;S18:7-12. 36 Crossey PA, Foster K, Richards FM, et al. Molecular genetic investigation of the mechanism of tumourigenesis in von Hippel-Lindau disease: analysis of allele loss in VHL tumours. Hum Genet 1994;93:53-8.

37 Gutmann DH, Geist RT, Rose K, Goran W, Moley JF. Loss of neurofibromatosis type 1 (NF1) gene expression in pheochromocytomas from patients without NF 1. Genes Chrom Cancer 1995;13:104-9. 